\title{
Dihydrolipoic acid reduces cytochrome b561 proteins
}

Alajos Bérczi ${ }^{(1)}$, László Zimányi ${ }^{(1)}$, Han Asard ${ }^{(2)}$

(1) Institute of Biophysics, Biological Research Centre, Hungarian Academy of Sciences, Temesvári krt. 62, H-6726 Szeged, Hungary, E-mail: berczi.alajos@ brc.mta.hu, Tel.: +36 62 599617, FAX.: +36 62433133

(2) Department of Biology, University of Antwerp, Campus Groenenborger, Groenenborgerlaan 171, B-2020 Antwerpen, Belgium

\begin{abstract}
Cytochrome $b 561$ (Cyt-b561) proteins constitute a family of trans-membrane proteins which are present in a wide variety of organisms. Two of their characteristic properties are the reducibility by ascorbate (ASC) and the presence of two distinct $b$-type hemes localized on two opposite sides of the membrane. Here we show that the tonoplast-localized (TCB) and the putative tumour suppressor (TSCB) Cyt- $b 561$ proteins can be reduced by other reductants than ASC and dithionite. A detailed spectral analysis of the ASC-dependent and dihydrolipoic acid (DHLA)dependent reduction of these two Cyt-b561 proteins are also presented. Our results are discussed in relation to the known antioxidant capability of DHLA as well as its role in the regeneration of other antioxidant compounds of cells. These results allow us to speculate on new biological functions for the trans-membrane Cyt-b561 proteins.
\end{abstract}

Keywords: Antioxidants, Ascorbate, Cytochrome $b 561$ proteins, Dihydrolipoic acid, SVD analysis, UV-VIS, 


\section{Introduction}

Cytochrome $b 561$ (Cyt-b561) proteins are ascorbate (ASC)-reducible, trans-membrane, di-heme proteins identified in a great variety of organisms, including invertebrates, vertebrates, and plants (Asard et al. 2001; Tsubaki et al. 2005; Glanfield et al. 2010). All Cyt-b561 proteins are predicted to consist of six trans-membrane helices, with four highly conserved His residues localized on four consecutive trans-membrane helices and likely involved in the coordination of the two hemes (Okuyama et al. 1998). One of their major properties is their significant reducibility by ASC, although many other $b$-type or $c$-type cytochromes can also be reduced by ASC. The first member of the Cyt-b561 protein family that was discovered is the chromaffin granule cytochrome $b 561$ (CGCB; Flatmark and Terland 1971). This protein was found to function as an electron transporter providing electrons from cytosolic ASC to intravesicular dopamine $\beta$-hydroxylase (Kelley and Njus 1986; Kent and Fleming 1987; Fleming and Kent 1991). CGCB is the only member of the protein family, however, that has so far been purified from its native membranes in sufficient amounts for biophysical or biochemical studies. It seems that other members of the protein family are present in a very small amount in their natural sources and appropriate amounts of these Cyt-b561 proteins could be obtained only after establishing a heterologous expression system for producing recombinant Cyt- $b 561$ proteins. Such expression systems were developed and successfully used in the characterization of CGCB (Bérczi et al. 2005; Liu et al. 2005, 2007), of the duodenum-localized Cyt-b561 (DCB; Ludwiczek et al. 2008; Oakhill et al. 2008), of the lysosome-localized Cyt- $b 561$ (LCB; Zhang et al. 2006), of the putative tumour suppressor Cytb561 (TSCB; Mizutani et al. 2007; Bérczi and Asard 2008; Recuenco et al. 2009), and of the tonoplast-localized Cyt-b561 (TCB; Griesen et al. 2004; Bérczi et al. 2007; Cenacchi et al. 2011) in the last 10 years. Only speculations exist, however, for the biological function of Cyt-b561 proteins other than CGCB and DCB (e.g. participation of TCB in iron redistribution in plant cells 
(Griesen et al. 2004; Preger et al. 2005) or participation in the energy dissipation (Nanasato et al. 2005)).

Alpha-Lipoic acid (LA) and its reduced form, dihydrolipoic acid (DHLA), are naturallyoccurring thiol compounds found ubiquitously in microorganisms, plants, and animals (Reed et al. 1974; Herbert and Guest 1975) and are potent antioxidants with capacity to scavenge reactive oxygen species (ROS) and recycle endogenous antioxidants (Packer et al 1995; Li et al 2004). In cells, very little lipoate exists in the free acid form; almost all is tethered to the $\varepsilon$-amino group of conserved lysine residues on lipoyl-accepting domains of proteins (Biewenga et al. 1997a; Booker 2004). DHLA is a metabolic product formed in vivo from LA (Biewenga et al. 1997b), which is widely used as a therapeutic agent in a variety of diseases. Clinical application of LA/DHLA includes treatment of excitotoxic amino acid brain injury, mitochondrial dysfunction, diabetes and diabetic neuropathy, inborn errors of metabolism, cataracts, glaucoma, ischemia-reperfusion injury, and mushroom poisoning (Packer et al. 1996; Nichols 1997). Several lines of evidence suggest that the antioxidant properties of LA/DHLA are, at least in part, responsible for the therapeutic effect. The antioxidant activity of LA/DHLA, however, was observed only in the presence of other compounds which act as antioxidant mediators, such as tocopherol, and only DHLA exerted the outstanding antioxidant activity (Kagan et al. 1992). It is widely accepted that LA/DHLA plays an important role in maintaining the redox status of cells and LA supplementation can enhance the antioxidant status of cells (Han et al 2008). Therefore, any new information on how LA/DHLA might interact with redox proteins in cells enriches our knowledge about the biological function of this redox couple.

The aim of this paper is to show that both a plant Cyt-b561 (TCB) and an animal Cyt-b561 (TSCB) can be reduced by DHLA almost as efficiently as by ASC. This result reveals the possibility of new potential biological functions of both Cyt-b561 proteins and the LA/DHLA redox couple. 


\section{Materials and Methods}

Cell growth, membrane preparation, protein purification

Yeast cell growth, microsomal membrane preparation, and protein purification by affinity chromatography were performed as detailed previously (Griesen et al. 2004; Bérczi and Asard 2008). Briefly, mouse (Mus musculus) TSCB (GenBank protein entry NP_062694) and mouse cress (Arabidopsis thaliana) TCB (GenBank protein entry NP_567723) with a C-terminal His $6^{-}$ tag, were cloned into a pESC(-His) expression vector (Stratagene, La Jolla. CA) and grown in yeast cells (Saccharomyces cerevisiae, strain YPH499: ura3-52 lys2-801 ${ }^{\text {amber }}$ ade2-101 ${ }^{\text {ochre }}$ trp1$\Delta 63$ his3- $\Delta 200$ leu2- $\Delta 1$ ) according to the manufacturer's instructions (Stratagene) at $30{ }^{\circ} \mathrm{C}$ in a bench-top incubator shaker (Excella E24R, New Brunswick Scientific Co., Edison, NJ, USA). Cells were broken by a bead-beater (Biospec Products, Bartlesville, OK, USA) and the stripped microsomal membrane fraction was obtained by differential centrifugation steps. Membrane vesicles were solubilised by $n$-dodecyl- $\beta$-D-maltopyranoside (DM) and the His $_{6}$-tagged recombinant proteins were purified to homogeneity by affinity chromatography using Ni-NTA His $\bullet$ Bind resin (Novagen, Madison, WI, USA). Purified TCB and TSCB were stored in phosphate buffer $\left(50 \mathrm{mM} \mathrm{NaH} \mathrm{PO}_{4}, \mathrm{pH} 7,10 \%(\mathrm{w} / \mathrm{v})\right.$ glycerol, $\left.0.5 \%(\mathrm{w} / \mathrm{v}) \mathrm{DM}\right)$ at $-80{ }^{\circ} \mathrm{C}$ until use. The very same phosphate buffer was used in all UV-VIS spectroscopy.

Protein was measured according to Markwell et al. (1978), using BSA as the standard and Na-deoxycholate as detergent, in the presence of phosphate buffer and DM, both in standards and in samples.

UV-VIS spectroscopy 
Absorption spectra were recorded in split beam mode (with buffer as reference) with an OLISupdated SLM-Aminco DW2000 spectrophotometer (OLIS Co., Bogart, GA, USA) with 2 nm slitwidth and under continuous stirring. The cuvette was equipped with a home-made lid for housing inert gas inlet-outlet tubing. Anaerobic conditions were created by continuous streaming of humidified Ar gas over the solution in the cuvette. Anaerobic measurements started after 15-20 min equilibration of the solution in the cuvette. The spectrum of the oxidized form of the proteins was recorded first and the dithionite-reduced spectrum was recorded last. When improvement of the signal-to-noise ratio was needed, multiple scans were averaged. Where mentioned, the cytochrome $b$ content was calculated from the dithionite-reduced minus ferricyanide-oxidized difference spectra by considering a molar extinction coefficient of $\varepsilon_{561 \mathrm{~nm}}=30 \mathrm{mM}^{-1} \mathrm{~cm}^{-1}$ (Tsubaki et al. 1997; Liu et al. 2005).

\section{Spectrum analysis}

Light scattering-related randomly varying baselines were subtracted from the absorption spectra to ensure isosbestic points of the oxidized and partially or fully reduced spectra at 544 and 572 $\mathrm{nm}$. The oxidized spectrum was subtracted from all consecutive spectra to generate a data matrix of reduced-minus-oxidized difference spectra (column vectors). To obtain the difference spectra corresponding to the individual hemes the data matrix was subjected to a chemometric analysis. Singular value decomposition (SVD; Shrager 1986; Henry and Hofrichter 1992) yielded a rank of 2 for the data matrices based on both the singular values and the autocorrelation of the spectral and titration eigenvectors (U and V vectors, respectively; Shrager 1986). Self-modelling (SM) in the two dimensional space of the $\mathrm{V}$ vectors was performed to calculate the combination coefficients and the corresponding difference spectra, which characterise the single-heme reduced-minus-oxidised forms of the protein (see results). The so obtained "pure" difference spectra were resolved into two Lorentzian bands and a skewed baseline as before (Bérczi et al. 
2010) to quantitatively characterize the spectra of the two hemes. All calculations were performed with Matlab (The MathWorks, Natick, MA).

Results are from one series of measurements but at least one more series of experiments with both TSCB and TCB gave similar results.

\section{Results and Discussion}

\section{Reducing agents}

All Cyt-b561 proteins can readily be reduced by ASC and dithionite (DTH), however, no experimental data have been published with respect to reducibility of any native or recombinant Cyt- $b 561$ by other potential reducing agents. Fig. 1 shows that both TCB and TSCB could be reduced not only by ASC and DTH but also by DHLA and dithiothreitol (DTT). Moreover, DHLA seemed to be as efficient as ASC, since both TCB and TSCB could be reduced to a similar extent at the same concentration $(1 \mathrm{mM})$ of the two reductants. However, neither reduced glutathione (GSH) nor reduced pyridine dinucleotides (NADH and NADPH) were capable of reducing either TSCB or TCB (not shown) even at $10 \mathrm{mM}$ concentration. Until now only Terland and Flatmark (1980) showed that CGCB in the highly purified chromaffin granule ghosts membranes, isolated from bovine adrenal medulla, could not be reduced by NADH. Lakshminarasimhan et al. (2006) also tested some reductants and measured the DHLA-dependent reduction of mouse recombinant CGCB. It was shown that DHLA could reduce CGCB but it appeared that only the so-called high-affinity-side (HA-side) heme was reduced. Similar studies have not been done with any other Cyt- $b 561$ protein yet. Our present results obtained with $\mathrm{NAD}(\mathrm{P}) \mathrm{H}$ and $\mathrm{GSH}$ as reducing agents support and verify the results mentioned above.

\section{Reduction by ASC and DHLA}


The reduction by ASC and DHLA were chosen for detailed spectral analysis, since these two reductants are natural compounds and are present in considerable concentration in both plant and animal cells. Furthermore, results have shown that the thiol groups in LA/DHLA might be involved in regeneration of ASC, vitamin E (tocopherol), glutathione, and ubiquinone (Bast and Haenen 1988; Scholich et al. 1989; Lykkesfeldt et al. 1998; Kozlov et al. 1999). It is widely accepted that LA/DHLA are present in cells mostly in lipoamine form, in which the 1,2-dithiolene moiety of LA/DHLA is linked to a lysine residue $\varepsilon$-amino group via a butyl arm and an amide bond. The lipoyl linkage provides rather high flexibility for the 1,2-dithiolane moiety, and the two -SH groups have the capability to reduce appropriate electron acceptors on the surface as well as below the surface of proteins. Furthermore, since CGCB is known to be involved in the transmembrane regeneration of ASC in the chromaffin granule (Srivastava et al 1984; Kent and Fleming 1987), we were interested to see in detail, and compare, the ASC- and the DHLAreducibility of the two different Cyt-b561 proteins.

Fig. 2 shows the concentration dependent reduction by ASC and DHLA of purified recombinant TCB (Fig. 2A) and TSCB (Fig. 2B) in detergent micelles given as gradual increase of the integral (between $550 \mathrm{~nm}$ and $570 \mathrm{~nm}$ ) of the $\alpha$-band (the $\mathrm{Q}_{0,0}$ band) of the reduced-minusoxidized absorption difference spectrum. With increasing concentration of reductants the level of reduction approaches (but never reaches) a saturation level. In case of TCB, (1) the ASCdependent reduction is very similar to that obtained earlier for the membrane-bound TCB (Bérczi and Asard 2006) and (2) similar levels of reduction need higher DHLA than ASC concentrations. In the case of TSCB, (1) the ASC-dependent reduction is very similar to that obtained earlier (Bérczi and Asard 2008) but (2) similar levels of reduction need lower DHLA than ASC concentrations and (3) already at the lowest DHLA concentration used $(1.5 \mu \mathrm{M})$ the protein is significantly reduced. If we characterize the concentration-dependent reduction of TCB and TSCB with the apparent affinity constants $\left(\mathrm{K}_{\mathrm{HA}}\right.$ and $\left.\mathrm{K}_{\mathrm{LA}}\right)$ used to fit the experimental results by 
single or double hyperbole (see the saturation curves in Figs. 2A and 2B) and compare the present results with those obtained earlier for the ASC- and DHLA-dependent reduction of CGCB (Bérczi et al. 2005; Lakshminarasimhan et al. 2006), the following observations can be made: (1) the ASC-dependent reduction of TCB $\left(\mathrm{K}_{\mathrm{HA}}=5.4 \mu \mathrm{M}, \mathrm{K}_{\mathrm{LA}}=336 \mu \mathrm{M}\right)$ is close to that of CGCB $\left(\mathrm{K}_{\mathrm{HA}}=16 \mu \mathrm{M}\right.$ and $21 \mu \mathrm{M}, \mathrm{K}_{\mathrm{LA}}=1.24 \mathrm{mM}$ and $\left.1.5 \mathrm{mM}\right)$, (2) the ASC-dependent reduction of $\operatorname{TSCB}\left(\mathrm{K}_{\mathrm{HA}}=268 \mu \mathrm{M}, \mathrm{K}_{\mathrm{LA}}=7.3 \mathrm{mM}\right)$ occurs at about 5 to 10 times higher ASC concentrations than that of CGCB, (3) the DHLA-dependent reduction of TCB $\left(\mathrm{K}_{\mathrm{HA}}=13.6 \mu \mathrm{M}, \mathrm{K}_{\mathrm{LA}}=291 \mu \mathrm{M}\right)$ occurs at slightly higher concentrations than the ASC-dependent reduction and shows two apparent affinities while that of CGCB $(K=71 \mu \mathrm{M})$ shows a single affinity, and (4) the DHLAdependent reduction of TSCB $(\mathrm{K}=137 \mu \mathrm{M})$ is close to that of CGCB. It is well seen that the high apparent affinity site for the DHLA reduction could not be resolved either earlier (in case of CGCB) or in this case with TSCB. Explanation for these differences remains the subject for further studies.

\section{Analysis of the absorption spectrum series}

SVD of the data matrices with the difference spectra as column vectors was performed and the singular values (in matrix $\mathrm{S}$ ) as well as the spectral (in matrix $\mathrm{U}$ ) and titration (in matrix V) eigenvectors inspected to determine the rank of the data matrices. Both the singular values and the autocorrelation of the eigenvectors confirmed a rank of 2 for the data matrices, indicating that the set of difference spectra can be adequately described by the evolution of two spectrally independent components during the titration (see also Bérczi et al. 2010). The two significant spectral eigenvectors for the ASC titration of TCB (data in Fig. 3A) are shown in Fig. 3B. The combination coefficients of these eigenvectors, i.e. the two titration eigenvectors are shown in Fig. $3 \mathrm{C}$ as a $\mathrm{V}_{1}-\mathrm{V}_{2}$ plot. Each measured spectrum in Fig. $3 \mathrm{~A}$ is represented in Fig. $3 \mathrm{C}$ as an open symbol. The evolution from the fully oxidized form (the origin, "ox:ox", as the analysis involves 
reduced minus oxidized spectra) towards the fully DTH-reduced form through increasingly more ASC-reduced states can be clearly followed. This plot eventually allows the construction of the individual spectra of the singly reduced species by SM (Zimányi 2004). It is reasonable to assume that at low ASC concentrations (first 4 symbols) only the HA-side heme is reduced, hence, a straight line connecting these points will lead to the combination coefficients and allow the construction of the spectrum of the singly reduced HA-side heme (see Fig. 3D). The direction of the evolution changes during the titration as the reduction of the LA-side heme sets in. At saturation with ASC both hemes are reduced to different extents. A species with the HA-side heme partially reduced and the LA-side heme still oxidized ( $\left.\operatorname{red}_{\mathrm{p}}: \mathrm{ox}\right)$ is obtained at the intersection of the lines connecting the first 4 data points and the next 8 data points. Conversely, a species with the HA-side heme oxidized and the LA-side heme partially reduced (experimentally not accessible) is calculated by subtracting the former species from the ASC-saturated spectrum. These two pure forms have been used to fit the spectrum of the fully (DTH-) reduced form in Fig. 3D. The fit is good, as shown by the residuals, and the obtained coefficients allow the calculation of the pure red:ox and ox:red spectra which are represented with their combination coefficients in Fig 3C. Earlier (Bérczi et al. 2010) the HA-side and LA-side heme spectra of TSCB were estimated by subtracting the oxidized spectrum from the partially ASC-reduced spectrum and the partially reduced one from the fully reduced one, yielding spectra closely resembling the ones calculated here.

Similar analyses were carried out for the DHLA titration of TCB and the ASC and DHLA titration of TSCB. The HA-side and LA-side (i.e. red:ox and ox:red) heme spectra obtained were identical, within the noise, for the ASC and DHLA titrations, but clearly distinct for the two proteins (Figs. 4A and 4D). The pure spectra from the ASC and DHLA titrations were averaged and resolved into two Lorentzian components (Fig. 4 B, C, E, F) and a skewed linear baseline. The parameters of the Lorentzian bands are summarized in Table 1. 
The most striking result obtained by the SVD-SM spectral analysis was the difference in the shape and relative location of the split $\alpha$-band absorption spectra of the HA-side hemes in TCB and TSCB (Fig. 4 and Table 1). In case of TCB, the split $\alpha$-band of the HA-side heme is slightly red-shifted compared to the split $\alpha$-band of the LA-side heme and the red-side peak of the split $\alpha$-band is higher than the blue-side peak. In contrast, in case of TSCB, the split $\alpha$-band of the HA-side heme is significantly blue-shifted compared to the split $\alpha$-band of the LA-side heme and the blue-side peak of the split $\alpha$-band is higher than the red-side peak. These spectral alterations might point to significant differences between the two heme-binding pockets. Although the amino acids of the two interloop regions between TM2 and TM3 as well as between TM4 and TM5 (Fig. 5) might be spatially rather far from the HA-side heme-binding pockets in both proteins, there is a considerable difference between the number of positively charged residues in these two interloop regions between TCB and TSCB. While there are only 5 Lys $(\mathrm{K})$ residues in the two interloops in TCB, there are $5 \operatorname{Arg}(\mathrm{R})$ and 4 Lys $(\mathrm{K})$ residues in TSCB. This difference might result in a significant difference in the electrostatic field at the HA-side heme-binding pocket in the two proteins, possibly resulting in significant differences in the location and shape of the split $\alpha$-band of the HA-side hemes. We should also recall that there is a significant difference between the location of the EPR signal attributed to the HA-side heme in TCB and TSCB (Bérczi et al. 2007, 2010; Desmet et al. 2011). While $g_{z}=3.14$ (Bérczi et al. 2007) and $g_{z}=3.16$ (Desmet et al. 2011) was obtained for the HA-side heme in TCB in sucrose monolaurate and DM micelles, respectively, a considerably lower value of $g_{z}=2.96$ (Bérczi et al. 2010) was obtained for the HAside heme in TSCB in DM micelles. The latter value raised the question whether the HA-side heme in TSCB is really coordinated by the two highly conserved His residues or if other hemecoordinating side chains may play a role in the HA-side heme binding. It seems that our present results support the EPR spectroscopy results indicating a significant difference between the HAside binding pockets in TCB and TSCB. 


\section{Physiological relevance and outlook}

Cyt-b561 proteins are members of a trans-membrane redox protein family found in animals, plants as well as bacteria. Their biological function(s), however, have not yet been fully elucidated. The most probable and widely accepted function (role) assumed is related to their ASC reducibility. Each Cyt-b561 is expected to participate in ASC metabolism and/or in iron acquisition (McKie et al. 2001; Asrad et al. 2003; Griesen et al. 2004; Tsubaki et al. 2005). LA/DHLA has recently gained substantial interest in biochemistry, food and pharmaceutical sciences as antioxidant, nutritional supplement and therapeutic agent (Packer et al. 1996, 1997; Li et al. 2004; Han et al. 2008). The mechanism(s) by which LA/DHLA can modulate cellular activities has(have) not yet been fully characterized. LA/DHLA content range between 5 and 25 nmoles per g fresh weight in mammalian tissues (Stokstad et al. 1956; Kataoka et al. 1993) or between 5 and $10 \mu \mathrm{g}$ per $\mathrm{g}$ fresh weight in chicken liver (Shih and Steinsberger 1981). Similar values are published for the LA/DHLA content in wheat roots and leaves (20-50 $\mu \mathrm{g}$ per g dry weight; Sgherri et al. 2002) but somewhat lower values have been reported for leaves, roots, and flowers of Arabidopsis (170, 90, and 290 ng per g fresh weight, respectively; Yasuno and Wada 1998), and for the14-day-old barley leaves (4-6 $\mu \mathrm{g}$ per g dry weight; Pérez-López et al. 2010). These values are equivalent to about 1-100 $\mu \mathrm{M}$ concentration at whole tissue level. However, we know very little about the compartmentalization and the LA/DHLA distribution. DHLA:LA ratios of 7-44 are measured, depending on the plant species and climate conditions studied (Sgherri et al. 2002; Pérez-López et al. 2010). Thus it seems that DHLA is the predominant form in biological tissues and local compartmental concentrations can be around $100 \mu \mathrm{M}$. According to our results $100 \mu \mathrm{M}$ DHLA is a concentration at which the TSCB and CGCB are partially reduced, while TCB reduction is hardly detectable. The significantly higher sensitivity of TSCB (and of CGCB) than of TCB to reduction by DHLA might point to a major and important difference between the mammalian and plant Cyt-b561 proteins. 
The rather low concentration of LA/DHLA in biological tissues, as compared to that of ASC/DHA and/or GSH/GSSG, might provide some explanation on why this redox couple, for a long time, has not been included in studies of metabolic regulation of redox pools in biological tissues. Our results connect the redox properties of Cyt- $b 561$ proteins and LA/DHLA. Based on the present observations it is theoretically possible that (1) ASC can be regenerated from ascorbyl free radicals by accepting electrons from Cyt- $b 561$ that was reduced by DHLA, (2) the LA/DHLA balance in cells is partly regulated/maintained by Cyt- $b 561$ proteins, and (3) Cyt-b561 proteins might play a significant role in the regulation and/or maintenance of the cellular redox status.

\section{Conclusion}

We have shown that two distinct recombinant Cyt-b561 proteins, TCB and TSCB, can be reduced not only by ASC and dithionite but also by other thiol-containing reductants, and cannot be reduced by the abundant and known cytosolic reductants, NAD $(\mathrm{P}) \mathrm{H}$ and GSH. DHLA that exists in cells mostly in protein-linked form is capable of reducing both Cyt-b561 proteins studied almost as efficiently as ASC. A detailed analysis of the split $\alpha$-band of the absorption spectra obtained after reduction by ASC or DHLA of highly purified TCB and TSCB has shown that, while the LA-side heme in the two proteins might have rather similar electronic states, the HAside hemes exhibit significantly different electronic states in these two Cyt- $b 561$ proteins. We speculate that the difference might be the result of the presence of more positively charged residues in two interloop regions in the vicinity of the HA-side heme-binding pocket of TSCB as compared to that of TCB. The present results may contribute to new views on the biological function of Cyt- $b 561$ proteins in connection to the biological importance of LA/DHLA in cells.

\section{Acknowledgements}


This work was supported by a grant of the Flemish Fund for Scientific Research (FWO;

G.0118.07N) to H.A., and by the Hungary-Romania Cross Border Cooperation Program of the EU (HURO/0901/219) to A.B. and L.Z. 


\section{References}

Asard H, Kapila J, Verelst W, Bérczi A (2001) Higher-plant plasma membrane cytochrome b561: a protein in search of a function. Protoplasma 217:77-93

Bast A, Haenen GRMM (1988) Interplay between lipoic acid and glutathione in the protection against microsomal lipid peroxidation. Biochim Biophys Acta 963:558-561

Bérczi A, Su D, Lakshminarasimhan M, Vargas A, Asard H (2005) Heterologous expression and site-directed mutagenesis of an ascorbate-reducible cytochrome $b 561$. Arch Biochem Biophys 443:82-92

Bérczi A, Asard H (2006) Characterization of an ascorbate-reducible cytochrome b561 by site directed mutagenesis. Acta Biol Szeged 50: 55-59

Bérczi A, Su D, Asard H (2007) An Arabidopsis cytochrome b561 with trans-membrane ferrireductase capability. FEBS Lett 581:1505-1508

Bérczi A, Asard H (2008) Expression and purification of the recombinant mouse tumor suppressor cytochrome $b 561$ protein. Acta Biol Szeged 52:257-265

Bérczi A, Desmet F, Van Doorslaer S, Asard H (2010) Spectral characterization of the recombinant mouse tumor suppressor 101F6 protein. Eur Biophys J 39:1129-1142

Biewenga GP, Haenen GRMM, Bast A (1997a) An overview of lipoate chemistry. In: Fuchs J, Packer L, Zimmer G (eds) Lipoic Acid in Health and Disease, Marcell Dekker, New York, USA, pp 1-32

Biewenga GP, Haenen GR, and Bast A (1997b) The pharmacology of the antioxidant lipoic acid. Gen Pharmacol 29:315-331

Booker SJ (2004) Unraveling the pathway of lipoic acid biosynthesis. Chem Biol 11:10-12

Cenacchi L, Busch M, Schleidt PG, Müller FG, Stumpp TVM, Mäntele W, Trost P, Lancaster CRD (2011) Heterologous production and characterization of two distinct diheam-containing 
membrane integral cytochrome b561 enzymes from Arabidopsis thaliana in Pichia pastoris and Escherichia coli cells. Biochim Biophys Acta (doi:10.1016/j.bbamem.2011.10.030)

Desmet F, Bérczi A, Zimányi L, Asard H, Van Doorslaer S (2011) Axial ligation of the highpotential heme center in an Arabidopsis cytochrome b561. FEBS Lett 585:545-548

Flatmark T, Terland O, (1971) Cytochrome $b_{561}$ of the bovine adrenal chromaffin granules. A high potential $b$-type cytochrome. Biochim Biophys Acta 253:487-491

Fleming PJ, Kent UM (1991) Cytochrome b561, ascorbic acid, and transmembrane electron transfer. Am J Clin Nutr 54:1173S-1178S

Glanfield A, McManus DP, SmythDJ, Lovas EM, Loukas A, Gobert GF, Jones MK (2010) A cytochrome b561 with ferric reductase activity from the parasitic blood fluke, Schistosoma japonicum. PLoS Negl Tropic Dis 4:e884

Griesen D, Su D, Bérczi A, Asard H (2004) Localization of an ascorbate-reducible cytochrome b561 in the plant tonoplast. Plant Physiol 134: 726-734

Han D, Hamilton RT, Lam PY, Packer L (2008) Modulation of cellular redox and metabolic status by lipoic acid. In: Petal MS, Packer L (eds) Lipoic Acid CRC Press, Boca Raton, Florida (USA), pp 293-314

Henry ER, Hofrichter J (1992) Singular value decomposition: Application to analysis of experimental data. Methods Enzymol 210:129-192

Herbert AA, Guest JR (1975) Lipoic acid content of Escherichia coli and other microorganisms. Arch Microbiol 106:259-266

Kagan VE, Shvedova A, Serbinova E, Khan S, Swanson C, Powell R, Packer L (1992)

Dihydrolipoic acid - A universal antioxidant both in the membrane and in the aqueous phase. Reduction of peroxyl, ascorbyl and chromanoxyl radicals. Biochem Pharmacol 44:1637-1649 Kataoka H, Hirabayashi N, Makita M (1993) Analysis of lipoic acid in biological samples by gas chromatography with flame photometric detection. J Chromatog 615:197-202 
Kelley PM, Njus D (1986) Cytochrome b561 spectral changes associated with electron transfer in chromaffin-vesicle ghosts. J Biol Chem 261:6429-6432

Kent UM, Fleming PJ (1987) Purified cytochrome $b_{561}$ catalyzes transmembrane electron transfer for dopamine $\beta$-hydroxylase and peptidyl glycine $\alpha$-amidating monooxygenase activities in reconstituted systems. J Biol Chem 262:8174-8178

Kozlov AV, Gille L, Stanick K (1999) Dihydrolipoic acid maintains ubiquinone in the antioxidant active form by two-electron reduction of ubisemiquinone. Arch Biochem Biophys 363:148154

Lakshminarasimhan M, Bérczi A, Asard H (2006) Substrate-dependent reduction of a recombinant chromaffin granule Cyt-b561 and its R72A mutant. Acta Biol Szeged 50: 61-65

Li Y, Zhao Y, Yu W, Jiang S (2004) Scavenging ability on ROS of alpha-lipoic acid (ALA) Food Chemistry 84: 563-567

Liu W, Kamensky Y, Kakkar R, Foley E, Kulmacz RJ, Palmer G (2005) Purification and characterization of bovine adrenal cytochrome b561 expressed in insect and yeast cell systems. Protein Expr Purif 40:429-439

Liu W, Rogge CE, Kamensky Y, Tsai A-L, Kulmacz RJ, (2007) Development of a bacterial system for high yield expression of fully functional adrenal cytochrome $b_{561}$. Protein Expr Purif 56:145-152

Ludwiczek S, Rosell FI, Ludwiczek ML, Mauk AG (2008) Recombinant expression and initial characterization of the putative human enteric ferric reductase Dcytb. Biochemistry 47:753761

Lykkesfeldt J, Hagen TM, Vladimir V, Ames BN (1998) Age-associated decline in ascorbic acid concentration, recycling, and biosynthesis in rat hepatocytes-reversal with (R)- $\alpha$-lipoic acid supplementation. FASEB Journal 12:1183-1189 
Markwell MAK, Haas SM, Bieber LL, Tolbert NE (1978) A modification of the Lowry procedure to simplify protein determinations in membrane and lipoprotein samples. Anal Biochem $87: 206-210$

McKie AT, Barrow D, Latunde-Dada GO, Rolfs A, Sager G, Mudaly E, Mudaly M, Richardson C, Barlow D, Bomford A, Peters RJ, Raja KB, Shirali S, Hediger MA, Farzaneh F, Simpson RJ (2001) As iron-regulated ferric reductase associated with the absorption of dietary iron. Science 291:1755-1759

Mizutani A, Sanuki R, Kakimoto K, Kojo S, Taketani S (2007) Involvement of 101F6, a homologue of cytochrome $b_{561}$, in the reduction of ferric ions. J Biochem 142:699-705

Nanasato Y, Akashi K, Yokota A (2005) Co-expression of cytochrome b561 and ascorbate oxidase in leaves of wild watermelon under drought and high light conditions. Plan Cell Physiol 46:1515-1524

Nichols TW (1997) Alpha-Lipoic Acid: Biological Effects and Clinical Implications. Alt Med Rev 2:177-183

Oakhill JS, Marritt SJ, Gareta EG, Cammack R, McKie AT (2008) Functional characterization of human duodenal cytochrome $b$ (Cybrd1): Redox properties in relation to iron and ascorbate metabolism. Biochim Biophys Acta 1777:260-268

Okuyama E, Yamamoto R, Ichikawa Y, Tsubaki M (1998) Structural basis for the electron transfer across the chromaffin vesicle membranes catalyzed by cytochrome b561: Analyses of cDNA nucleotide sequences and visible absorption spectra., Biochim Biophys Acta $1383: 269-278$

Packer L, Witt EH, Tritschler HJ (1995) Alpha-lipoic acid as a biological antioxidant. Free Radic Biol Med 19:227-250

Packer L, Tritschler HJ, Wessel K (1996) Neuroprotection by the metabolic antioxidant alphalipoic acid. Free Radic Biol Med 22:359-378 
Packer L, Roy S, Sen CK (1997) $\alpha$-Lipoic acid: A metabolic antioxidant and potential redox modulator of transcription. In: Sies H (ed) Advances in Pharmacology, Vol. 18, Antioxidants in Disease Mechanisms and Therapy, Academic Press, San Diego, CA (USA), pp 79-101

Pérez-López U, Robredo A, Lacuesta M, Sgherri C, Mena-Petite A, Navari-Izzo F, Muñoz-Rueda A (2010) Lipoic acid and redox status in barley plants subjected to salinity and elevated $\mathrm{CO}_{2}$. Physiol Plant 139:256-268

Preger V, Pesaresi A, Pupillo P, Trost P (2005) Identification of an ascorbate-dependent cytochrome $\mathrm{b}$ of the tonoplast membrane sharing biochemical features with members of the cytochrome b561 family. Planta 220:365-375

Recuenco MC, Fujito M, Rahman M, Sakamoto Y, Takeuchi F, Tsubaki M (2009) Functional expression and characterization of human 101F6 protein, a homologue of cytochrome b561 and a candidate tumor suppressor gene product. Biofactors 34:219-230

Reed LJ (1974) Multienzyme complexes. Acc Chem Res 7:40-46

Scholich H, Murphy ME, Sies H (1989) Antioxidant activity of dihydrolipoate against microsomal lipid peroxidation and its dependence on $\alpha$-tocopherol. Biochim Biophys Acta $1001: 256-261$

Sgherri C, Mike F. Quartacci MF, Izzo R, Navari-Izzo F (2002) Relation between lipoic acid and cell redox status in wheat grown in excess copper. Plant Physiol Biochem 40:591-597

Shih JCH, Steinsberger SC (1981) Determination of lipoic acid in chicken livers and chicken eggs during incubation. Anal Biochem 116:65-68

Shrager RI (1986) Chemical transition measured by spectra and resolved using singular value decomposition. Chemometr Intell Lab Systems 1:59-70

Srivastava M, Duong LT, Fleming PJ (1984) Cytochrome b561 catalyzes transmembrane electron transfer. J Biol Chem 259:8072-8075

Stokstad ELR, Seaman GR, Davis RJ, Hutner SH (1956) Assay of thioctic acid. In: Glick D (ed) Methods of biochemical analysis, Vol. 3, Wiley, New York, pp. 23-47 
Terland O, Flatmark T (1980) Oxidoreductase activities of chromaffin granule ghosts isolated from the bovine adrenal medulla. Biochim Biophys Acta 597:318-330

Tsubaki M, Nakayama M, Okuyama E, Ichikawa Y, Hori H (1997) Existence of two heme B centers in cytochrome $b 561$ from bovine adrenal chromaffin vesicles as revealed by a new purification procedure and EPR spectroscopy. J Biol Chem 272:23206-23210

Tsubaki M, Takeuchi F, Nakanashi N (2005) Cytochrome b561 protein family: Expanding roles and versatile transmembrane electron transfer abilities as predicted by a new classification system and protein sequence motif analyses. Biochim Biophys Acta 1753:174-190

Tusnády GE, Simon I (1998) Principles governing amino acid composition of integral membrane proteins: application to topology prediction. J Mol Biol 283:489-506

Tusnády GE, Simon I (2001) The HMMTOP transmembrane topology prediction server. Bioinformatics 17:849-850

Verelst W, Asard H (2003) A phylogenetic study of cytochrome b561 proteins. Genome Biol $4: \mathrm{R} 38$

Yasuno R, Wada H (1998) Biosynthesis of Lipoic Acid in Arabidopsis: Cloning and Characterization of the cDNA for Lipoic Acid Synthase. Plant Physiol 118:935-943

Zhang D, Su D, Bérczi A, Vargas A, Asard H (2006) An ascorbate-reducible cytochrome b561 is localized in macrophage lysosomes. Biochim Biophys Acta 1760:1903-1913

Zimányi L (2004) Analysis of the bacteriorhodopsin photocycle by singular value decomposition with self-modeling: a critical evaluation using realistic simulated data. J Phys Chem B 108:4199-4209 


\section{Figure legends}

Fig. 1. Reduction by different reducing agents of purified TCB (A) and TSCB (B) in detergent micelles and in phosphate buffer $\left(50 \mathrm{mM} \mathrm{NaH}_{2} \mathrm{PO}_{4}, 10 \%\right.$ (w/v) glycerol, $\left.0.5 \mathrm{mM} \mathrm{DM}, \mathrm{pH} 7\right)$. Spectra shown are the reduced-minus-oxidized difference spectra in the presence of $1 \mathrm{mM}$ or 10 $\mathrm{mM}$ reducing agents.

Fig. 2. Concentration dependent reduction of purified TCB (A) and TSCB (B) by ASC (A, from 1 $\mu \mathrm{M}$ to $10 \mathrm{mM}$; B, from $10 \mu \mathrm{M}$ to $115 \mathrm{mM}$ ) and DHLA (A, from $1 \mu \mathrm{M}$ to $10 \mathrm{mM}$; , from $1.5 \mu \mathrm{M}$ to $10 \mathrm{mM}$ ) in detergent micelles. The relative values of reduction were obtained as follows. The integral of the $\alpha$-band between $550 \mathrm{~nm}$ and $570 \mathrm{~nm}$ was taken and a single or double saturation curve was fitted to the integral values obtained. All experimental values and the fitting curves are normalized with the calculated saturation value of the ASC titration and the normalized values are presented at different reductant concentrations.

Fig. 3. Determination of the reduced-minus-oxidized difference absorption spectra of the high and low affinity-side hemes of TCB from the ASC titration by SVD-self-modelling. (A) Concentration dependent reduction of purified TCB by ASC in detergent micelles (from the bottom to the top curve the concentrations are from $1 \mu \mathrm{M}$ to $10 \mathrm{mM}$ ). (B) The two significant spectral eigenvectors. (C) The $\mathrm{V}_{1}-\mathrm{V}_{2}$ plot corresponding to the experimental spectra (open circles), the fully oxidized and fully (DTH-) reduced spectra (the latter shown in D), and locations corresponding to the partially and fully reduced HA-side and LA-side hemes with the other heme oxidized (see text for details). (D) Experimental difference spectrum of the fully (DTH-) reduced TCB, calculated spectra corresponding to the species with singly reduced hemes and the difference between the fully reduced spectrum and the sum of the two singly reduced spectra (marked as residuals). Gray code corresponds to the symbols in C. 
Fig. 4. Fit of the high affinity $(B, E)$ and low affinity $(C, F)$ heme difference spectra for TCB (AC) and TSCB (D-F). (A, D) Calculated high and low affinity spectra from the ASC (black) and DHLA (gray) titrations. (B, C, E, F) The averages of the calculated difference spectra from the ASC and DHLA titrations are fitted by two Lorentzian components plus a skewed linear baseline (not shown). The gray curves are the residuals of the fits.

Fig. 5. Comparison of the primary structure of the CB domain region (Verelst and Asard 2003) of the Bos taurus CGCB (Bot-CGCB), Arabidopsis thaliana TCB (Art-TCB), and Mus musculus TSCB (Mum-TSCB). The four highly conserved His residues $(\mathrm{H})$, the two bis-His coordinated hemes (the thick bars with central circle between the $\mathrm{H}$ residues), and the four consecutive transmembrane helices (TM2 through TM5; bold and underlined amino acids) are shown. HA-side heme is seen between TM3 and TM5, LA-side heme is seen between TM2 and TM4. The putative ascorbate free radical binding motif (SLHSW) in the vicinity of the LA-side heme and the putative ASC binding motif (ALLVYRVFRN) in the vicinity of the HA-side heme in CGCB are boxed. Multiple alignment was obtained by CLUSTALW2 (http://www.ebi.ac.uk/Tools/clustalw2/index.html). Trans-membrane helices were obtained by using the HMMTOP prediction (Tusnády and Simon 1998, 2001). 
Table 1. Parameters used for the fit of the split $\alpha$-band of the HA-side and LA-side hemes in TCB and TSCB.

\begin{tabular}{|c|c|c|c|c|c|c|c|c|}
\hline & Peak position & Error & Peak width & Error & Peak height & Error & Peak separation & Error \\
\hline TCB & $\mathrm{nm}$ & $\mathrm{nm}$ & $\mathrm{nm}$ & $\mathrm{nm}$ & & & $\mathrm{nm}$ & $\mathrm{nm}$ \\
\hline HA heme & 558.52 & 0.32 & 4.9948 & 0.4381 & 0.0259 & 0.0023 & 6.34 & 0.35 \\
\hline & 564.86 & 0.14 & 4.5811 & 0.2507 & 0.0484 & 0.0026 & & \\
\hline LA heme & 557.77 & 0.30 & 5.1980 & 0.3522 & 0.0395 & 0.0028 & 5.68 & 0.34 \\
\hline & 563.45 & 0.15 & 3.7103 & 0.2850 & 0.0431 & 0.0034 & & \\
\hline TSCB & & & & & & & & \\
\hline HA heme & 554.54 & 0.12 & 5.4533 & 0.2433 & 0.0157 & 0.0004 & 8.35 & 0.18 \\
\hline & 562.89 & 0.13 & 4.0438 & 0.3032 & 0.0099 & 0.0005 & & \\
\hline LA heme & 556.89 & 0.22 & 2.9742 & 0.3967 & 0.0063 & 0.0008 & 5.46 & 0.27 \\
\hline & 562.35 & 0.16 & 4.8803 & 0.2415 & 0.0186 & 0.0007 & & \\
\hline
\end{tabular}


Fig. 1.
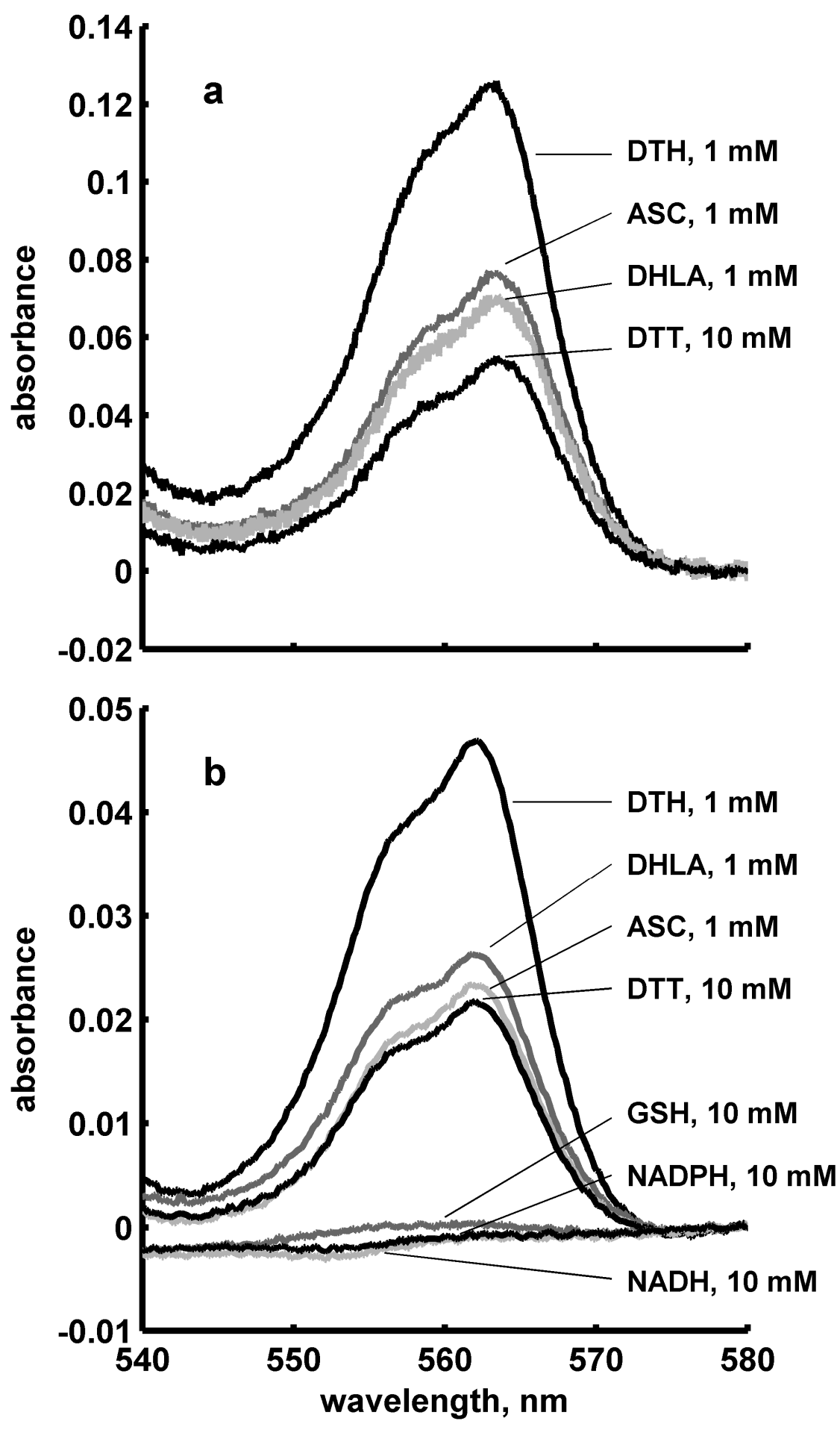
Fig. 2.
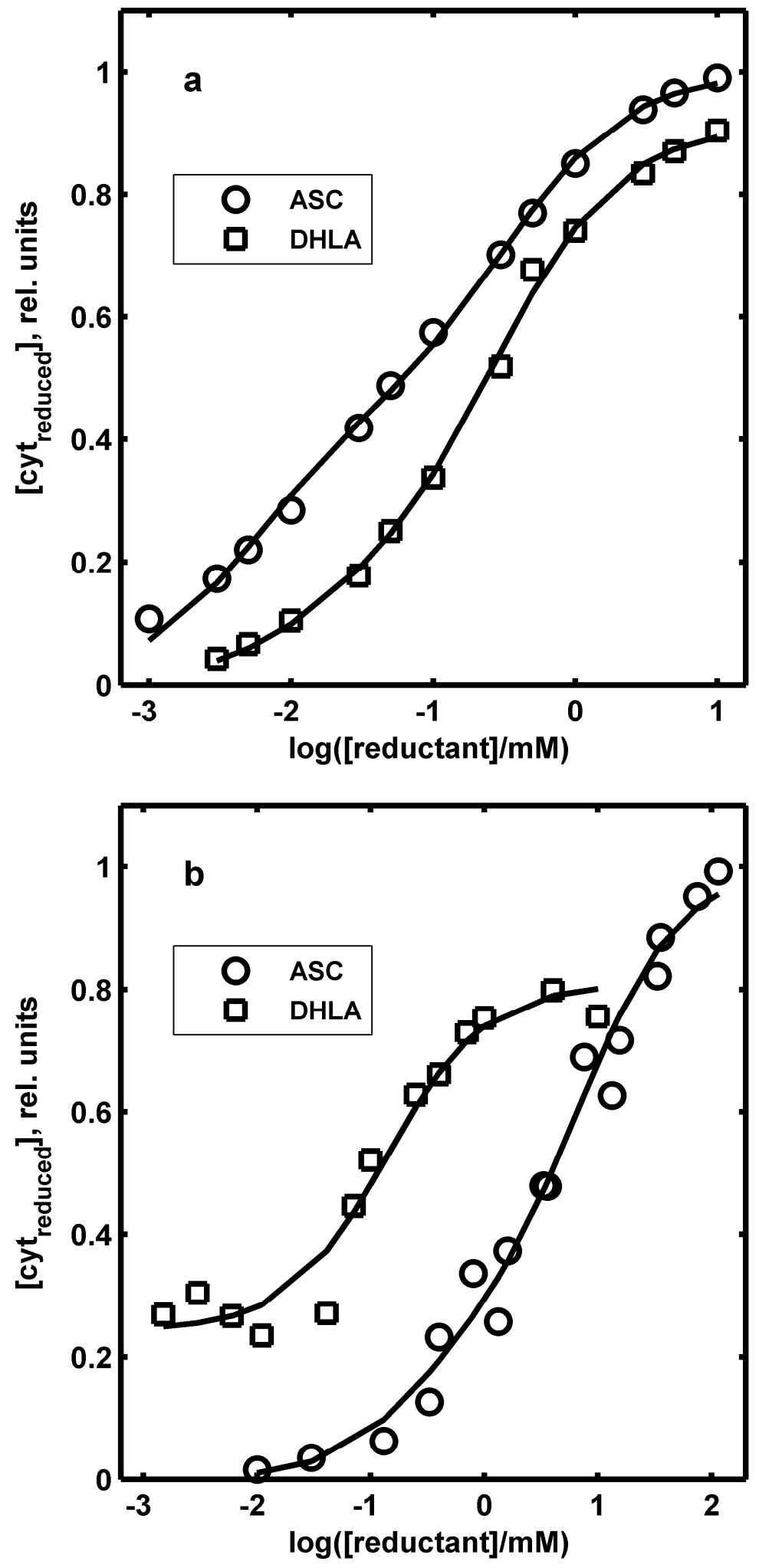
Fig. 3.
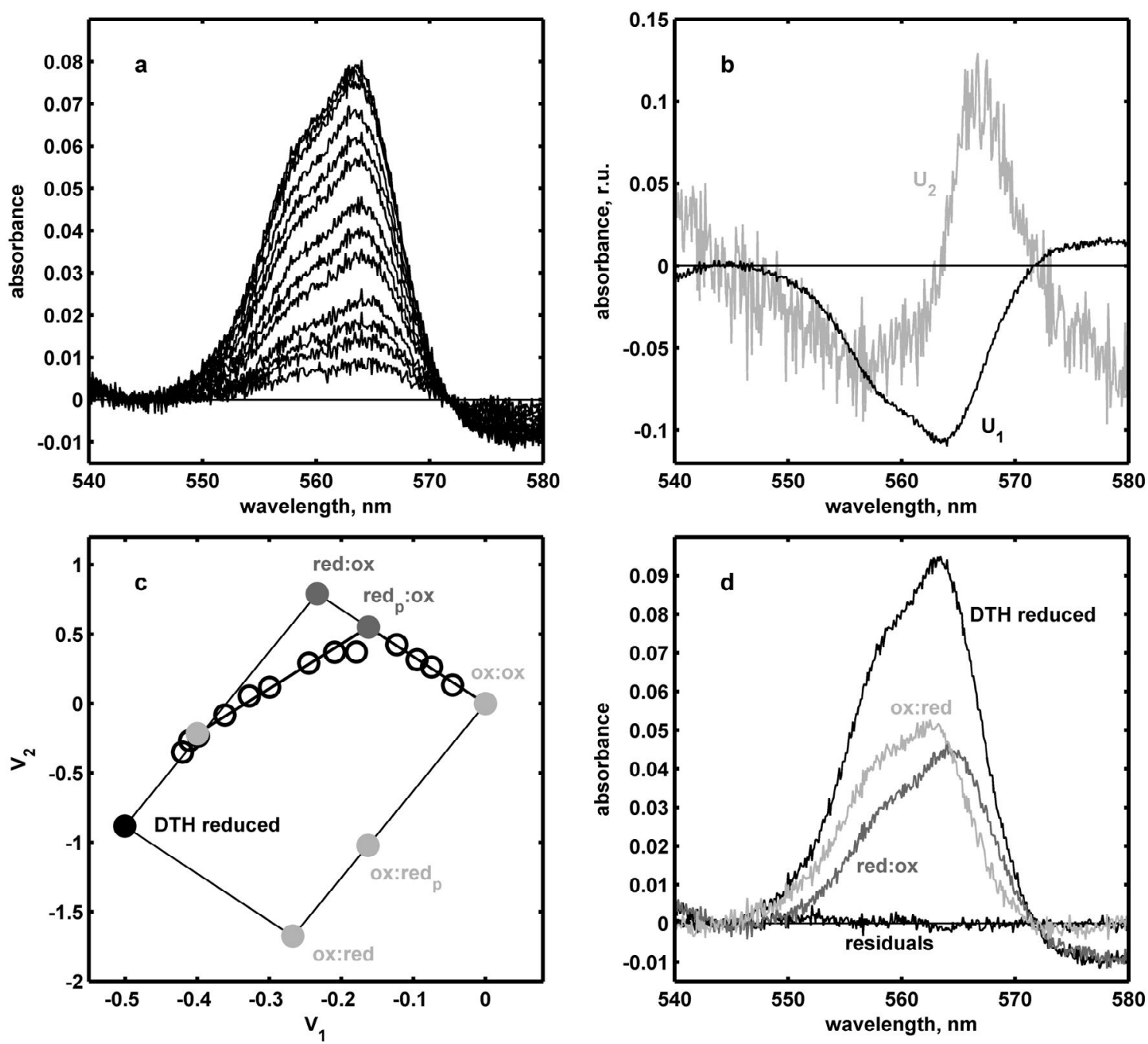
Fig. 4.
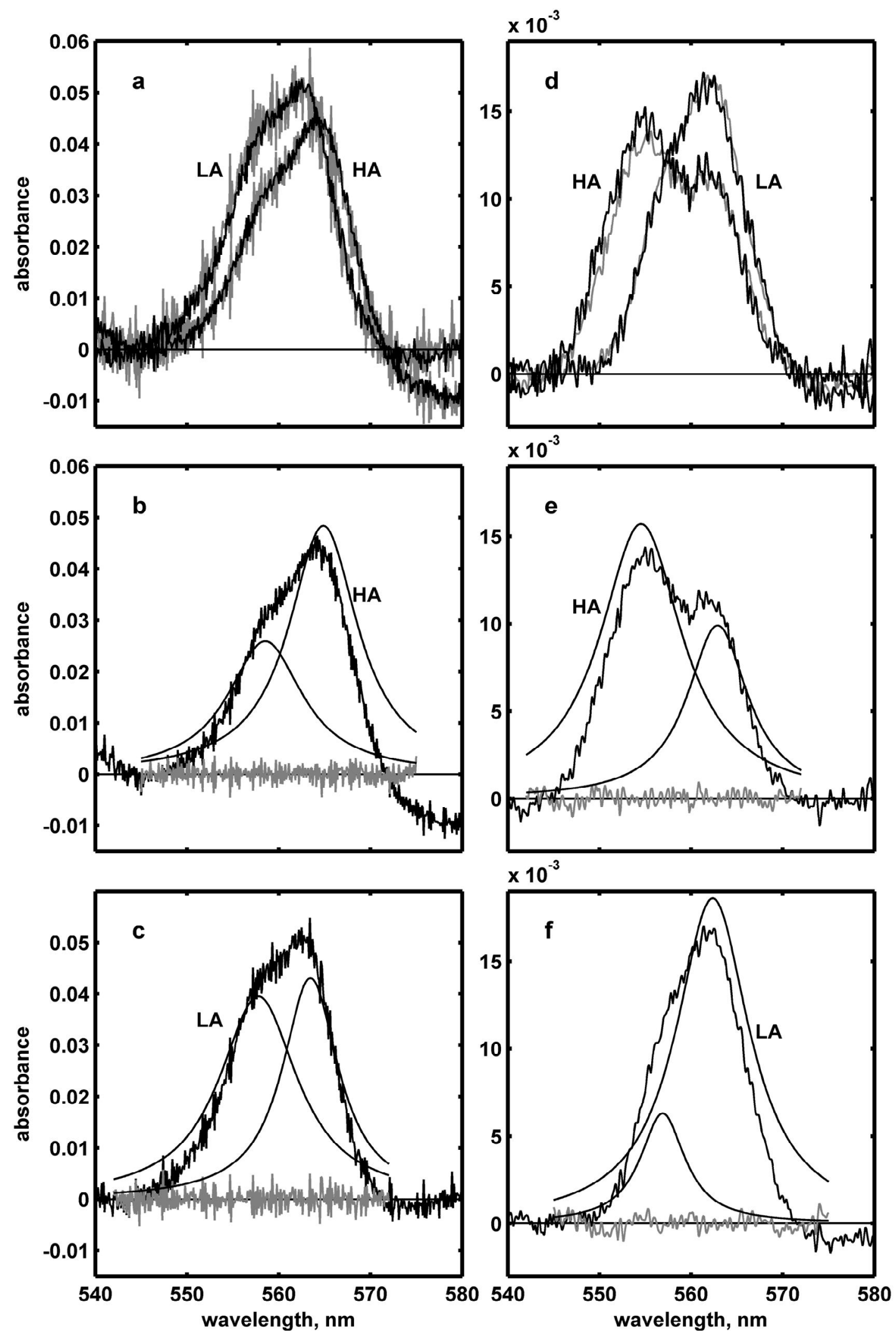
Fig. 5.

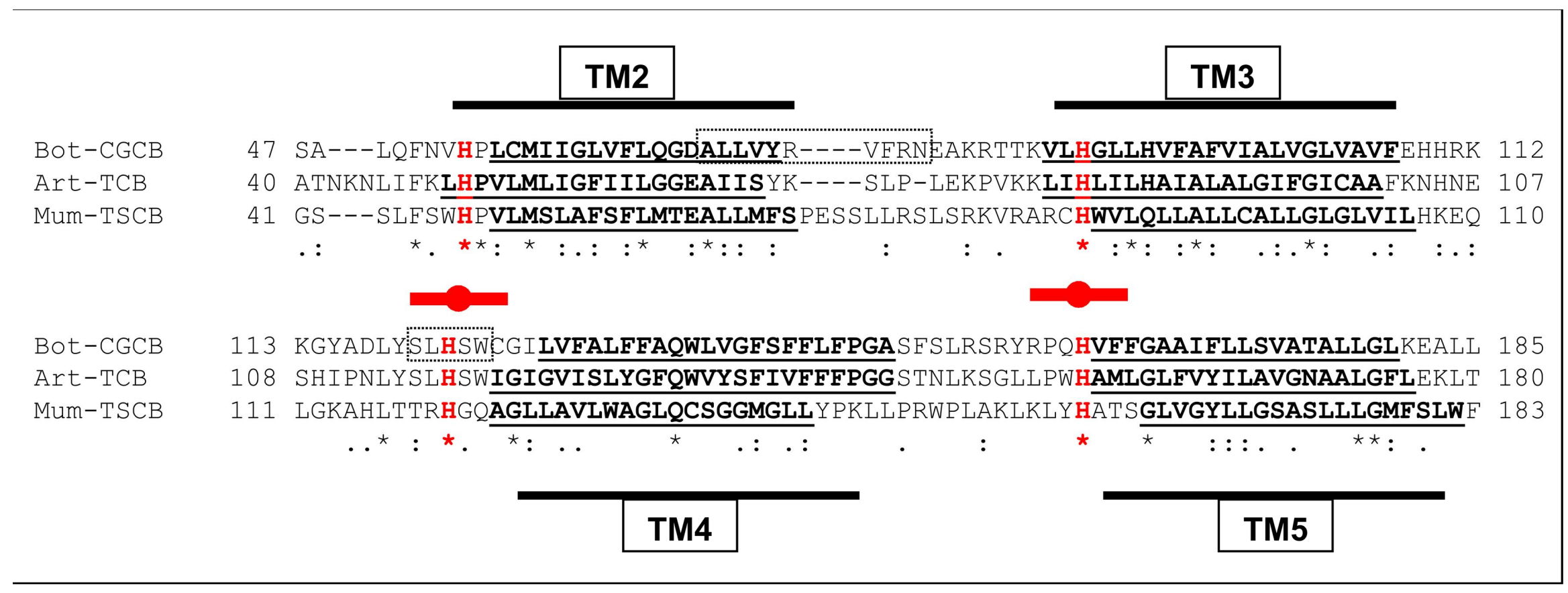

